\title{
MODELLING OF UNCERTAINTY IN MINIMISING THE COST OF INVENTORY FOR DISASTER RELIEF
}

\author{
E. van Wyk ${ }^{1^{*}}$, W.L. Bean ${ }^{2}$ and V.S.S. Yadavalli ${ }^{3}$ \\ ${ }^{1,3}$ Department of Industrial and Systems Engineering \\ University of Pretoria, South Africa \\ estelle.vanwyk@up.ac.za, sarma.yadavalli@up.ac.za \\ ${ }^{2}$ Logistics and Quantitative Methods \\ CSIR Built Environment, South Africa \\ wbean@csir.co.za
}

\begin{abstract}
Natural disasters - and even those caused by people - are largely unpredictable. So disasters need to be researched and their impact fully understood, so that the aid supplies required to ensure survival during and after disaster events will be available. The member states of the Southern African Development Community (SADC) are the countries of interest for this paper, as insufficient research has been conducted into inventory pre-positioning for disaster response in these countries. It is vital to anticipate the needs of disaster victims in potential disasters. These needs are evaluated according to the types and amounts of aid supplies required. This paper proposes a stochastic inventory model that can be applied in a generic way to any SADC country, providing a means to improve disaster preparedness through keeping aid supplies in pre-positioned facilities in the SADC region, at reasonable and affordable cost.
\end{abstract}

\section{OPSOMMING}

Natuurlike en mensgemaakte rampe is grootliks onvoorspelbaar. Gevolglik moet rampe nagevors en hul impak ten volle begryp word, sodat noodvoorrade wat benodig word vir oorlewing doeltreffend beplan kan word vir aanwending tydens en na rampgebeure. Die lede van die Suid-Afrikaanse Ontwikkelingsgemeenskap (SAOG) is die lande van belang vir hierdie artikel omrede navorsing oor voorraadhouding vir rampreaksie in hierdie betrokke lande tot nog toe onvoldoende was. Dit is noodsaaklik om doeltreffend in die behoeftes van rampslagoffers te voorsien. Hierdie behoeftes word beoordeel na aanleiding van die aard en hoeveelhede van noodvoorrade wat benodig mag word in ramptoestande. Hierdie artikel stel ' $n$ stochastiese voorraadmodel voor vir toepassing op ' $n$ generiese wyse in enige SAOG land, om sodoende 'n metode te verskaf om rampvoorbereiding te verbeter deur die opgaar van noodvoorrade in vooraf-geïdentifiseerde fasiliteite binne die SAOG, teen redelike en bekostigbare koste.

\footnotetext{
${ }^{1}$ The author was enrolled for a B Eng (Industrial) degree in the Department of Industrial and Systems Engineering, University of Pretoria.

"Corresponding author.
} 


\section{INTRODUCTION}

In November 1998, Hurricane Mitch, a 180 -mph category storm, swept through Central America, devastating the economies of Honduras, Nicaragua, and Guatemala. An estimated 10,000 people died, while two million were left homeless. In response to the disaster, Carlos Flores, the President of Honduras, said: "We lost in 72 hours what had taken us more than 50 years to build, bit by bit" [17].

The International Federation of Red Cross and Red Crescent Societies (IFRC) was not prepared for the disaster, and failed to manage it. The IFRC's failure to consider the prepositioning of supplies caused a slow inflow of relief supplies, and so staff were not sufficiently prepared to respond to the crisis [17].

Throughout history and around the world, disasters have caused endless suffering, loss of human life, and environmental damage [21]. Thousands of people are affected annually by both natural and human-caused disasters that, according to the Centre for Research on the Epidemiology of Disasters [7], are increasing substantially, leading to a greater need for efficient disaster management.

Tomasini \& Wassenhove [19] define 'disaster management' as the result of a long and structured process of strategic process design, ultimately resulting in successful execution [20]. Disaster management can be divided into four phases: mitigation, preparedness, response, and recovery. These phases are known collectively as the disaster operations life cycle. Mitigation is the application of measures that either prevent the onset of a disaster or reduce the impact in the event of a disaster. Preparedness relates to the community's ability to respond when a disaster occurs. Response refers to the use of resources and emergency procedures, guided by plans to preserve life, property, and the governing structure of the community. Finally, recovery involves actions taken to stabilise the community following the immediate impact of a disaster [1].

Tomasini \& Wassenhove [19] emphasise that the first 72 hours after a disaster are crucial to saving the greatest number of human lives. Saving lives, however, relies on the correct quantity and types of aid supplies - which would be a fairly effortless resolution if all disaster effects could be predicted.

Because of this complexity, it is vital that relief supplies be pre-positioned to improve emergency response times. This forms part of the preparedness phase in the disaster operations life cycle. Demand for aid supplies will vary in type and quantity depending on the specific disaster and the level of destruction it causes. These supplies must meet the immediate needs of those affected, and will include food, medicine, tents, sanitation equipment, tools, and related necessities [22].

Given the problem of preparing for a disaster, a research gap has been identified for the pre-positioning of aid supplies in Southern Africa; and so this paper will focus on the countries that are member states of the Southern African Development Community (SADC) [21]. Potential disasters facing these countries are identified, as well as the associated inventory that would be necessary for survival. Even though programmes are in place to improve disaster preparedness in these countries [11], the lack of research could lead to inadequate solutions regarding the quantity and type of aid supplies required in a prepositioning facility.

The SADC consists of the majority-ruled states in Southern Africa: Angola, Botswana, the Democratic Republic of Congo, Lesotho, Madagascar, Malawi, Mauritius, Mozambique, Namibia, Seychelles, South Africa, Swaziland, Tanzania, Zambia, and Zimbabwe [14]. These countries have been susceptible to natural and man-made disasters in the past. Natural disasters have occurred in the form of drought, famine, earthquakes, epidemics, extreme temperatures, floods, storms, and wildfires. Man-made disasters have occurred in the form of industrial accidents, transport accidents (road, rail, and air), terrorism, political 
instability, and crime [7]. The timeframe considered for this project spans 30 years, from the year of the formal establishment of the SADC in 1980 to 2009 [21].

Research shows that most SADC countries have been greatly affected by drought, floods, and epidemics [7]. Transport accidents, and specifically road accidents, make up a major man-made disaster [7]. By identifying the most frequent disasters, it is possible to establish the supplies that are essential for surviving these disasters.

We encourage the formulation of a mathematical model to help anticipate the types and quantities of aid supplies to be kept in a pre-positioned facility, at the lowest viable cost. The number of people affected per event will simplify determining the quantities of aid supplies. The amount of supplies required per person will then be multiplied by the number of persons affected, to arrive at an estimate of the total quantity of supplies required to survive such eventualities. These quantities are used as part of the input for the model.

The remainder of this paper is structured as follows: A literature review addresses the problem variants associated with disaster relief and existing models that have been developed to accommodate these areas. The research methodology presents the stochastic inventory model formulated to determine effectively the types and amounts of aid supplies for the SADC countries. The results and findings address the computational results of the model. The paper concludes with future research developments and propositions.

\section{LITERATURE REVIEW}

A considerable amount of the literature has addressed the management of disaster relief organisations [21]. Much of it deals with the social and organisational implications of responding to disasters in all parts of the world, including areas that may lack infrastructure and/or may be involved in hostilities [20]. According to Turoff [20], information systems applications have improved greatly over the past few years and have helped to reduce the impact of disaster events. Offsetting this, however, are the forces of population increases, human encroachment into high-risk areas, and changing climate patterns [20]. Despite the progress that disaster planning, mitigation, and new management systems have made, the need for relief remains when such disasters occur [22]. Improving disaster relief planning and management is a continuous process [21].

Due to the unpredictable nature of a disaster, disaster management is a process that cannot be one hundred percent controlled [21]. Altay \& Green [1] point out that, even though it is known that response to disasters requires good planning, it is crucial to leave room for improvisation in order to deal with the unusual challenges that are created. Hills [10] supports this notion by saying that the phrase "disaster management" implies a degree of control that rarely exists in disaster cases. It is for this reason that standard management methods used in the industry may not always apply directly to disaster situations [1].

Rawls \& Turnquist [16] raise another concern: that the capacities of resource providers are the key components in managing response efforts following disaster events, but that only a small amount of research has been conducted into the planning of aid supplies kept in inventory at pre-positioned facilities. In addition, Duran et al. [9] maintain that an important assumption to take into account when considering stock pre-positioning is that facilities should always have sufficient inventory to satisfy demand. It should also be remembered that stored aid supplies might be destroyed during a disaster event [9]. The pre-positioned stock should thus meet the needs of a disrupted region by taking the effect of the disaster into consideration [4]. The above-mentioned problem variants should be addressed by focusing on the uncertainty of a disaster and on how demand can be addressed [21].

The majority of favourable solutions to disaster management problems are supported by mathematical programming methods such as operations research. This is described by Mete \& Zabinsky [15] as an appropriate tool for planning the preparedness phase of disaster 
management, due to its ability to handle uncertainty by means of probabilistic scenarios that represent disasters and their outcomes. Very few journal articles address inventory control problems that are related to humanitarian relief [21].

Rawls \& Turnquist [16] present a two-stage stochastic mixed integer program that provides an emergency response pre-positioning strategy for disaster threats. The algorithm is formulated as a heuristic algorithm. The model considers uncertainty in demand for stocked supplies, but also includes the uncertainty regarding transportation network availability after an event. For the purpose of this paper, only inventory decisions were considered.

A stochastic inventory control model is developed by Beamon \& Kotleba [3] in the form of $\left(Q_{1}, Q_{2}, r_{1}, r_{2}\right)$. The model uses optimal order quantities and re-order points to determine inventory for a pre-positioned warehouse responding to a complex humanitarian emergency, including the exceedingly variable demand on the warehouse supply items [3]. The model allows for two types of order lot sizes: $Q_{1}$ for a regular order, and $Q_{2}$ for an urgent order. $Q_{1}$ is ordered when the inventory reaches level $r_{1}$, and $Q_{2}$ is ordered when the inventory level reaches $r_{2}$, where $r_{1}>r_{2}$. Beamon \& Kotleba [3] use simulation to compare the optimal solution of the $\left(Q_{1}, Q_{2}, r_{1}, r_{2}\right)$ model with a heuristic and naïve inventory model for a pre-positioned warehouse. This approach does not specify the types of inventory required, only the quantities; and it was therefore not appropriate to use as a solution model for this paper.

Bryson et al. [4] use optimal and heuristic approaches to solve a number of hypothetical problems. Mixed integer programming is applied to establish the disaster recovery capability of an organisation. The aim of the model is to determine the resources that should be used in order to maximise the total expected value of the recovery capability. The use of mathematical modelling provides an appropriate decision support tool for the successful development of a disaster recovery plan (DRP). This model provides a generic approach that considers the different types of resources required to satisfy the demand induced by any relevant disaster.

Van Wyk et al. [21] regard the model developed by Bryson et al. [4] to be applicable to the SADC countries, and adapt it to support the decision-maker with inventory decisions for disaster relief within the SADC. The approach is to maximise the total recovery capability of any country in the region to provide relief for as many disaster victims as possible.

A Markovian process is also used to solve the demand distribution of inventory. This idea was initiated by Karlin \& Fabens [12], claiming that if each demand state is defined by different numbers, a base stock type inventory policy can be obtained. Taskin \& Lodree [18] use stochastic programming to determine an optimal order policy so that the demand in each pre-hurricane season period is met, and so that reserve supplies are stored for the ensuing hurricane season in a cost-effective way. This model provides a valid solution if the decision-maker is concerned with providing relief at a minimum cost.

Taskin \& Lodree [18] present a meaningful solution to the problem variants. With the help of their model, an appropriate model is formulated to comply with SADC requirements.

\section{RESEARCH METHODOLOGY}

Humanitarian relief organisations aim to provide relief for as many disaster victims as possible, subject to limited funding. It is therefore useful to consider a model that helps the decision-maker with inventory decisions at the lowest possible cost. The notations of the stochastic inventory model for the SADC are addressed below:

$Q_{i k} \triangleq$ The number of aid supplies $i$ required for demand scenario $k$

$c_{i} \triangleq$ The unit ordering cost of aid supply $i$

$x_{i k} \triangleq$ The total expected demand for aid supply $i$ for demand scenario $k$

$q_{k} \triangleq$ The probability of a scenario $k$ 
$v_{i k} \triangleq$ The excess inventory of aid supply $i$ for scenario $k$

$h_{i} \triangleq$ The unit holding cost of aid supply $i$

$u_{i k} \triangleq$ The number of shortages of aid supply $i$ observed for scenario $k$

$s_{i} \triangleq$ The shortage cost of aid supply $i$

These notations are used to formulate the following objective function:

$\min z=\sum_{i=1}^{I} \sum_{k=1}^{K} q_{i k}\left(c_{i} Q_{i k}+h_{i} v_{i k}+s_{i} u_{i k}\right)$

subject to

$Q_{i k}+u_{i k}-v_{i k}=x_{i k}$

$Q_{i k}, v_{i k}, u_{i k} \geq 0 \quad \forall \quad i \in I, \quad k \in K$

The objective function selects the appropriate quantities and types of aid supplies to minimise the overall cost of inventory kept. Constraint (2) guarantees that the number of aid supplies required for a demand scenario corresponds with the expected demand of a scenario, while taking excess inventory and shortages into consideration. Constraint (3) ensures that decision variables $Q_{i k}, v_{i k}$ and $u_{i k}$, remain greater than or equal to 0 . It is assumed that no excess inventory is present during the first usage of the model.

The model was adapted to apply to the SADC region, and so a few assumptions are changed to convert the model into a more appropriate solution. Taskin \& Lodree [18] use two different time periods that are now discarded to simplify the model for the various disaster scenarios and aid supplies. The inventory kept is considered for a period of one year. Thus it is suggested that the model should be revisited once a year with updated data, assuming that a disaster has occurred.

According to Taskin \& Lodree [18], only one type of item is considered; but the model formulated for the SADC will include all the aid supplies selected to provide relief. The final adjustment is made to the unit cost $s_{i}$ of an aid supply, which is changed to the shortage cost of an item. It is crucial to address shortage cost, considering that human lives are at stake.

These adaptations ensure that the model is suitable for the various disasters and their impact in the SADC.

\section{RESULTS AND FINDINGS}

This section describes the computational results of the model. The generic inventory model was coded in LINGO version 8.0, on a standard personal computer, rendering a result in less than 9 seconds. The model has a total of 561 variables and 749 constraints. A short description of how the relevant parameter values were obtained is addressed, followed by the results of the model and the sensitivity analysis used to test the functionality of the model.

For the purpose of the second model, it was necessary to identify disaster scenarios or, more simply stated, disaster impact. To analyse a scenario effectively, all the possible characteristics of a disaster - that is, disaster types and effects - have to be considered. Therefore, for each disaster type and each related effect, a probability is determined, which is multiplied to obtain a disaster scenario. Figure 1 illustrates this method. 


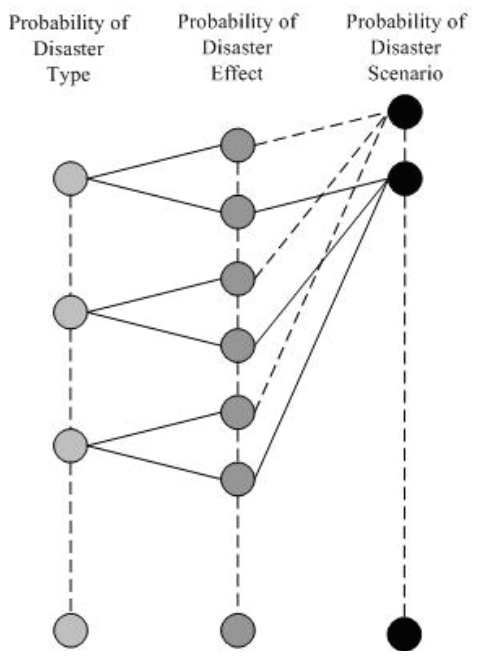

Figure 1: Determining scenario probabilities

Predicting a disaster is challenging, and in most cases impossible. However, a probability can be determined to pre-determine the likelihood of such an event. The approach used to determine these probabilities was to observe the number of times the identified disasters had occurred in the SADC in the past 30 years. The total number of occurrences of each disaster is then divided by the overall total of all the SADC disasters, presented in Table 1. The stochastic model considers the probability that a disaster has failed to take place within a given year in the 30 year period. Table 1 displays these probabilities.

\begin{tabular}{llrr}
\hline No. & Disaster & Total & Probability \\
\hline 1 & Drought & 70 & 0.01341 \\
2 & Earthquake & 17 & 0.00326 \\
3 & Epidemic & 154 & 0.02950 \\
4 & Extreme temperature & 2 & 0.00038 \\
5 & Flood & 168 & 0.03218 \\
6 & Industrial accident & 26 & 0.00498 \\
7 & Insect infestation & 5 & 0.00096 \\
8 & Mass movement wet & 4 & 0.00077 \\
9 & Miscellaneous accident & 28 & 0.00536 \\
10 & Storm & 100 & 0.01916 \\
11 & Transport accident & 298 & 0.05709 \\
12 & Wildfire & 12 & 0.00230 \\
13 & No disaster & 4,336 & 0.83065 \\
\hline & Total & 5,220 & 1 \\
\hline
\end{tabular}

Table 1: Probability of a disaster occurrence

In addition to identifying the frequency of each disaster occurrence, it is important to understand all the disaster impacts. Therefore the repetition of a disaster and its effect is determined. The disaster effects were identified in ten different ranges of population affected. These ranges were estimated by considering all the data of the disasters that affected population groups in the SADC during the selected period. The percentiles of the list of values were determined by computing the $10^{\text {th }}$ percentile, $20^{\text {th }}$ percentile, and so on up to the $100^{\text {th }}$ percentile; and from these the ranges were developed. This method was used to anticipate that a country with a smaller population is also incorporated when affected by the worst possible eventuality. Effect 1 thus represents no disaster, and effect 11 the worst potential disaster. By identifying each frequency it was possible to compute 
the probable effect of a defined disaster, determined by dividing each value by the associated totals.

Referring back to Figure 1, the probability of a disaster scenario is obtained by multiplying the probability of each similar disaster effect by the probability of every disaster type, and adding these values. Table 2 shows the related probabilities, which represent the parameter $q_{k}$.

\begin{tabular}{lc}
\hline Scenario $k$ & Probability \\
\hline 1 (No effect) & 0.9090 \\
2 & 0.0096 \\
3 & 0.0086 \\
4 & 0.0094 \\
5 & 0.0090 \\
6 & 0.0084 \\
7 & 0.0092 \\
8 & 0.0092 \\
9 & 0.0094 \\
10 & 0.0090 \\
11 & 0.0092 \\
\hline Total & 1 \\
\hline
\end{tabular}

Table 2: Probability of a scenario $\left(\boldsymbol{q}_{k}\right)$

To determine the parameter $x_{i k}$, the total expected demand is calculated for aid supply $i$ for demand scenario $k$. The quantities of these supplies, however, are determined by establishing the required demand for every possible disaster scenario. The total supply of all the items will be sufficient for 30 days, which according to Kovacs \& Spens [13] is enough time for the recovery phase to be planned. The unit ordering costs $c_{i}$ of each item are obtained from appropriate suppliers.

The final parameters to be considered are the holding cost $h_{i}$ and the shortage cost $s_{i}$. To emphasise the significance of these costs, Kovacs \& Spens [13] raise the following question:

How to balance the costs of shortages and/or holding inventory with human suffering, and should they be balanced?

Due to the complications that arise when determining these costs for humanitarian organisations, the assumption is made that when any shortages are present, it simply means that there is an insufficient quantity of relief supplies for disaster victims, resulting in a possible loss of life. Therefore, the shortage cost is determined as follows:

Shortage cost $=($ Monetary value of human life $\times$ Probability that item $i$ will be required) $\times$ Number of persons that can utilise one unit

It may seem insensitive and inhumane to place a monetary value on human life, but to estimate the value of a treatment or solution to save a life, it is necessary to determine such value [5]. In addition, by not assigning a selected monetary value to human life in relation to the shortage costs associated with humanitarian organisations, it could be considered careless if just any random value is selected.

The monetary value of a life for the purpose of this model is determined by using the fatal injury cost per person from the national Department of Transport in South Africa [8]. The estimated value is ZAR 529,459.

The probability that an aid supply will be required is simply the sum of the probabilities of the disasters in which the aid supply is demanded. 
Holding cost comprises the cost of carrying one unit of inventory for one time period, and usually includes storage and insurance cost, taxes on inventory, labour cost, and cost of spoilage, theft, or obsolescence [23]. Unlike supply and distribution cost, not all humanitarian relief chains will have substantial inventory cost, in that some relief organisations will maintain and operate their own supply warehouses [2]. The holding costs will therefore depend entirely on the decision-maker's personal preference and demand. Factors such as the size of the warehouse, number of staff, and insurance rates need to be considered. Because of the implications involved in determining these factors, the holding costs will be computed as a percentage of the unit cost of each item. The inventory carrying cost will vary according to each individual warehouse, but for testing purposes it is assumed that inventory carrying cost equals $25 \%$ of product value per annum [6].

In the first instance, the stochastic inventory model is tested by using the defined parameters addressed above. The graph in Figure 2 illustrates the resulting quantities and types of aid supplies required. The results show that, as the scenario effects worsen, the quantity of aid supplies do not increase accordingly. The model is concerned with the minimum cost of inventory kept, and so it attempts to provide sufficient relief while avoiding unnecessary costs. Table 3 illustrates the individual values of each aid supply.

To test the functionality of the model further, a sensitivity analysis is conducted. The method used is to alternate the holding and shortage cost, while the other parameters are kept constant. The shortage cost is alternated with nine consecutive progressive ranges of values, while the holding cost remains constant. Thereafter, the holding cost is alternated with nine consecutive progressive ranges of values, while the shortage cost remains constant. Figure 3 shows how the overall cost given by the objective function remains constant with each progressive range. The graph shows that, when the holding cost is kept constant, the total cost is presented as an acceptable minimum value as long as the shortage cost is kept as low as possible, and the same result is shown when the holding cost is kept at a minimum. From this graph it can be concluded that the model will provide a reasonably low overall cost if holding and shortage costs are kept as low as possible.

The model evidently provides a means to determine the quantities and types of aid supplies to be kept in a pre-positioned facility at the lowest possible cost. The model identifies the required inventory to be kept for one year, and to be revisited annually with updated data to provide relief for the following year.

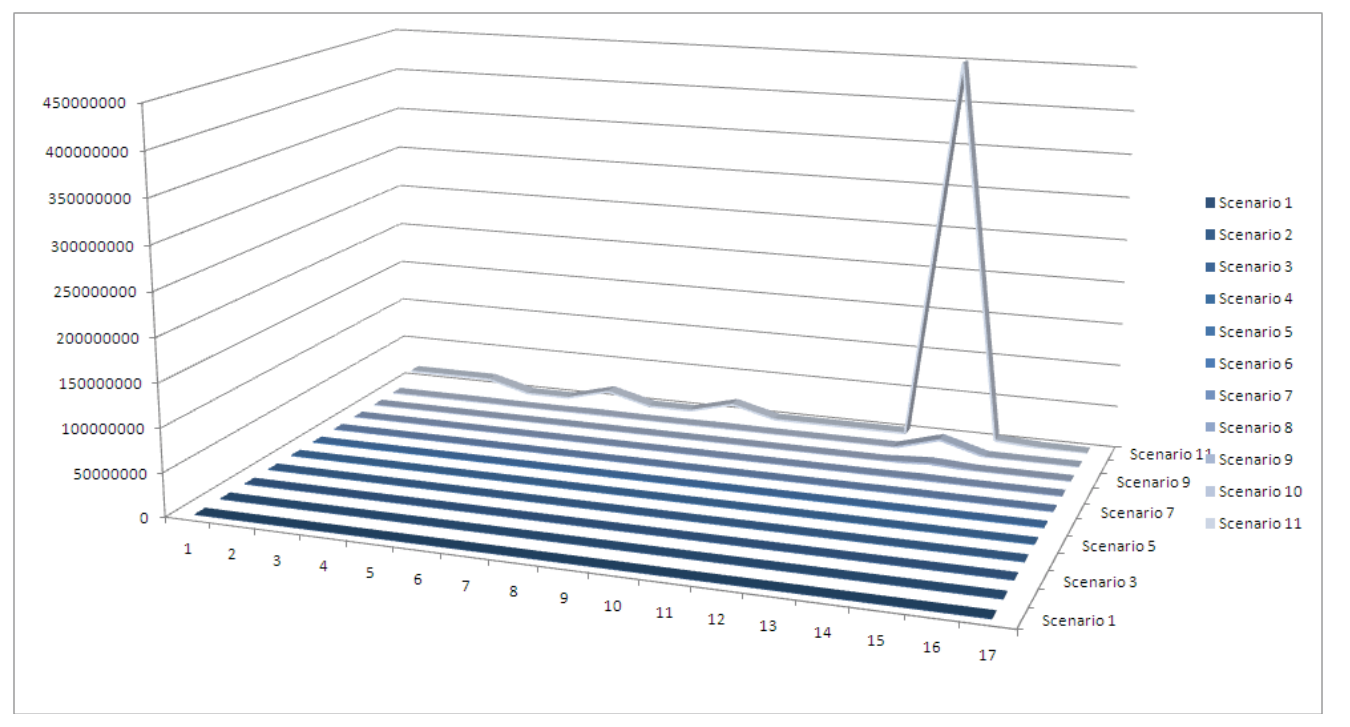

Figure 2: Model results: Quantities and types of aid supplies 


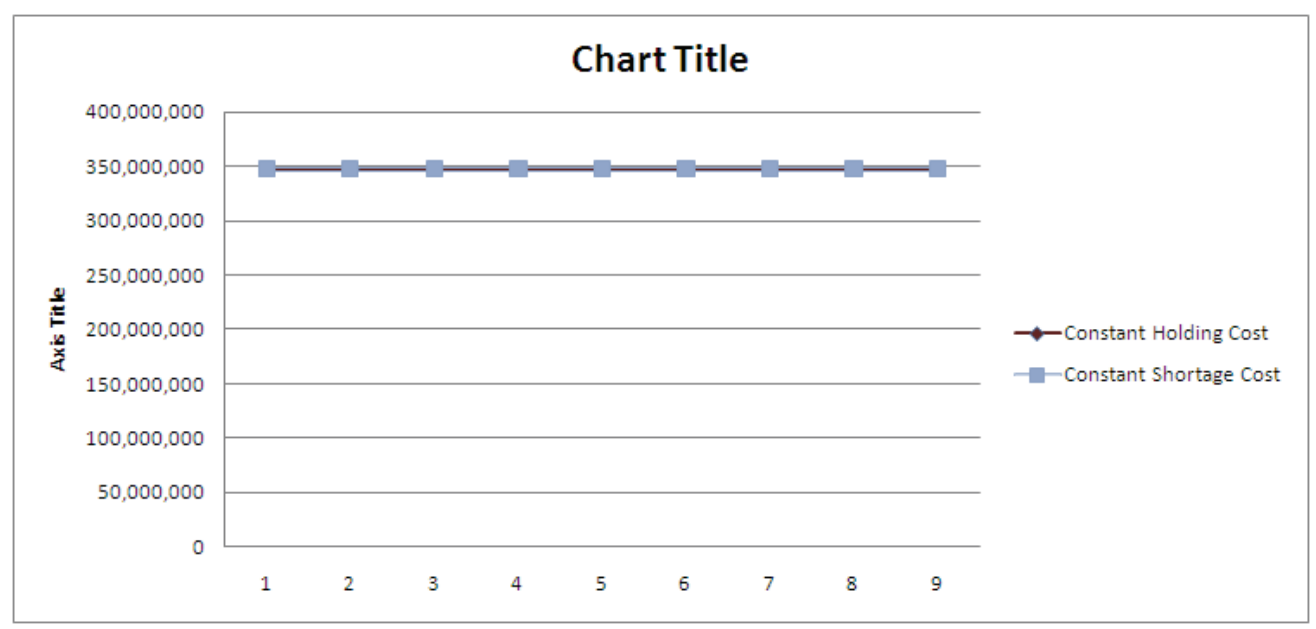

Figure 3: Effect of alternating holding and shortage costs

\begin{tabular}{|c|c|c|c|c|c|c|c|c|c|c|c|}
\hline \multicolumn{12}{|c|}{$K$} \\
\hline$I$ & 1 & 2 & 3 & 4 & 5 & 6 & 7 & 8 & 9 & 10 & 11 \\
\hline 1 & 0 & 40 & 100 & 300 & 900 & 3000 & 10000 & 23000 & 102000 & 505000 & 15000000 \\
\hline 2 & 0 & 40 & 100 & 300 & 900 & 3000 & 10000 & 23000 & 102000 & 505000 & 15000000 \\
\hline 3 & 0 & 40 & 100 & 300 & 900 & 3000 & 10000 & 23000 & 102000 & 505000 & 15000000 \\
\hline 4 & 0 & 4 & 10 & 30 & 90 & 300 & 1000 & 2300 & 10200 & 50500 & 1500000 \\
\hline 5 & 0 & 4 & 10 & 30 & 90 & 300 & 1000 & 2300 & 10200 & 50500 & 1500000 \\
\hline 6 & 0 & 40 & 100 & 300 & 900 & 3000 & 10000 & 23000 & 102000 & 505000 & 15000000 \\
\hline 7 & 0 & 4 & 10 & 30 & 90 & 300 & 1000 & 2300 & 10200 & 50500 & 1500000 \\
\hline 8 & 0 & 4 & 10 & 30 & 90 & 300 & 1000 & 2300 & 10200 & 50500 & 1500000 \\
\hline 9 & 0 & 40 & 100 & 300 & 900 & 3000 & 10000 & 23000 & 102000 & 505000 & 15000000 \\
\hline 10 & 0 & 4 & 10 & 30 & 90 & 300 & 1000 & 2300 & 10200 & 50500 & 1500000 \\
\hline 11 & 0 & 4 & 10 & 30 & 90 & 300 & 1000 & 2300 & 10200 & 50500 & 1500000 \\
\hline 12 & 0 & 4 & 10 & 30 & 90 & 300 & 1000 & 2300 & 10200 & 50500 & 1500000 \\
\hline 13 & 0 & 4 & 10 & 30 & 90 & 300 & 1000 & 2300 & 10200 & 50500 & 1500000 \\
\hline 14 & 0 & 1200 & 3000 & 9000 & 27000 & 90000 & 300000 & 690000 & 3060000 & 15150000 & 450000000 \\
\hline 15 & 0 & 11 & 27 & 82 & 245 & 818 & 2727 & 6273 & 27818 & 137727 & 4090909 \\
\hline 16 & 0 & 2 & 5 & 15 & 45 & 150 & 500 & 1150 & 5100 & 25250 & 750000 \\
\hline 17 & 0 & 1 & 1 & 3 & 8 & 25 & 83 & 192 & 850 & 4208 & 125000 \\
\hline
\end{tabular}

Table 3: Model results

\section{CONCLUSION AND FUTURE WORK}

The aim of this paper is to show how mathematical modelling can provide strategic decision support for selecting the required amount and types of aid supplies to be kept in inventory in a pre-positioning facility within the SADC countries. The stochastic inventory model is 
concerned with minimising the total costs incurred when accumulating and storing relief supplies.

Future research development of the model can be made by gathering data from other countries and applying the model to such preselected regions. The pre-processing of the model showed that the difficulty of determining holding and shortage costs for humanitarian organisations was overcome by assigning a monetary value to human life, and incorporating the value as part of the holding and shortage costs. To improve on this approach and increase the functionality and reliability of the model, it can be converted into its dual composition structure.

\section{MANAGERIAL IMPLICATIONS AND RECOMMENDATIONS}

To emphasise the importance of managing disaster-related activities, it is imperative to address the managerial implications of such activities.

The aid sector lacks operational knowledge, and is not up to date with the latest methods and techniques available to solve disaster relief complexities [13]. Even though this paper presents an appropriate method for disaster preparedness, it will not achieve its full potential if the other phases in the disaster operations life cycle are not properly planned and managed. All four phases need good collaboration and coordination to complete a successful life cycle. A humanitarian organisation can be well-prepared for a disaster, but severe implications will arise if the response and recovery phase are not properly managed [21].

Another implication to be considered is that, although a pre-positioned facility can be effectively stocked with the correct amounts and types of aid supplies, the logistics of receiving the items from suppliers and transporting these supplies to disaster-affected areas are a vital managerial responsibility. The inventory for disaster relief must be kept up to date, with reference to the quantity and types of aid supplies. Some countries have poor infrastructure, and so transport and pre-positioning need to be well prepared. The final consideration is the prevention of crime, such as theft, which is a concern in certain countries within the SADC. Consequently a pre-positioned facility should be fully equipped with security measures [21].

A closer look at humanitarian logistics thus shows that risk management, crisis management, continuity planning, and project management form an important part of the logistics process. For a successful recovery from a disaster, organisations need to incorporate these managerial processes into the disaster operations life cycle, which will lead to an increasing assurance that lives will be saved [21].

Future studies can complement this work by applying operational research methods to the other phases in the disaster operations life cycle.

Due to the useful results provided by both models, their implementation will effectively assist and guide decision-makers with inventory decisions for disaster relief. With adequate marketing, the model can be implemented by humanitarian organisations.

From a decision-maker's point of view, the model can serve as a handy guideline when planning the types and quantities of aid supplies that should be kept so that lives are saved, rather than lost through insufficient preparedness. The results of the model indicate that workable solutions have been identified that might increase the use of operational research methods to enhance disaster relief decision-making. In conclusion, this paper challenges the fatal effects of disasters by providing instruments to overcome some of the difficulties of disaster management. 


\section{REFERENCES}

[1] Altay, N. \& Green, W.G. 2006. OR/MS research in disaster operations management. European Journal of Operations Research, 175, pp 475-493.

[2] Beamon, B.M. \& Balcik, B. 2008. Performance measurement in humanitarian relief chains. International Journal of Public Sector Management, 21, pp 4-25.

[3] Beamon, B.M. \& Kotleba, S. 2006b. Inventory modelling for complex emergencies in humanitarian relief operations. International Journal of Logistics: Research and Applications, 9(1), pp 1-18.

[4] Bryson, K-M.N., Millar, H., Joseph, A. \& Mobolurin, A. 2002. Using formal MS/OR modelling to support disaster recovery planning. European Journal of Operations Research, 141, pp 679-688.

[5] Card, W.I. \& Mooney, G.H. 1977. What is the monetary value of a human life? British Medical Journal, 2, pp 1627-1629.

[6] Coyle, J.J., Bardi, E.J., \& Langley Jr., C.J.. 2003. The management of business logistics: A supply chain perspective. Thomson Learning.

[7] CRED. 2009. Country profiles. Technical report, Centre for Research on the Epidemiology of Disasters. Available online from http://www.emdat.be/disasterprofiles/. Retrieved 12 March 2010.

[8] De Beer, E.J.H. \& Van Niekerk, E. 2004. The estimation of unit costs of road traffic accidents in South Africa. Technical report, National Department of Transport.

[9] Duran, S., Gutierrez, M.A. \& Keskinocak, P. 2009. Pre-positioning of emergency items worldwide for CARE International. INFORMS. Doi: 10.1287.

[10] Hills, A. 1998. Seduced by recovery: The consequences of misunderstanding disaster. Journal of Contingencies and Crisis Management, 6(3), pp 162-170.

[11] IFRC. 2009. Disaster reduction programme 2001-2008. International Federation of Red Cross and Red Crescent Societies. Available online from http://www.ifrc.org/ Docs/pubs/disasters/resources/reducing-risks/dr-programme-en.pdf. Retrieved 12 March 2010.

[12] Karlin, S. \& Fabens, A. 1960. The (s,S) inventory model under Markovian demand process. Mathematical Methods in the Social Sciences (Chapter 8), pp 159-175.

[13] Kovacs, G. \& Spens, K.M. 2007. Humanitarian logistics in disaster relief operations. International Journal of Physical Distribution and Logistics Management, 37(2), pp 99-114.

[14] Leichenko, R.M. \& O'Brien, K.L. 2002. The dynamics of rural vulnerability to global change: The case of Southern Africa. Mitigation and Adaption Strategies for Global Change, 7, pp 1-18.

[15] Mete, H.O. \& Zabinsky, Z.B. 2009. Stochastic optimization of medical supply location and distribution in disaster management. International Journal of Production Economics. Doi: 10.1016/j.ijpe.2009.10.004.

[16] Rawls, C.G. \& Turnquist, M.A. 2009. Pre-positioning of emergency supplies for disaster response. Transportation Research, Part B. Doi: 10.1016/j.trb.2009.08.003.

[17] Samii, R. \& Wassenhove, L.V. 2002. IFRC Choreographer of Disaster Management Hurricane Mitch. Technical report, INSEAD Case Study No.06/ 2002-5039.

[18] Taskin, S. \& Lodree, E.J.J. 2009. Inventory decisions for emergency supplies based on hurricane count predictions. International Journal of Production Economics, Doi: 10.1016/jipe.2009.10.008, pp 1-10.

[19] Tomasini, R. \& Wassenhove, L.V. 2009. Humanitarian logistics. Palgrave Macmillan.

[20] Turoff, M. 2002. Past and future emergency response information systems. Communications of the ACM, 45, 29-33.

[21] Van Wyk, E., Yadavalli, V.S.S. \& Bean, W. 2011. Strategic inventory management for disaster relief. To appear in Management Dynamics, 2011.

[22] Whybark, D. 2007. Issues in managing disaster relief inventories. International Journal of Production Economics, 108, 228-235.

[23] Winston, W.L. 2004. Introduction to probability models, Volume 2. Curt Hinrichs, $4^{\text {th }}$ edition. 
